\title{
Ice Accretion Modeling using an Eulerian Approach for Droplet Impingement
}

\author{
Jee Woong Kim ${ }^{l}$, Dennis P. Garza ${ }^{2}$, Lakshmi N. Sankar ${ }^{3}$ \\ School of Aerospace Engineering, Georgia Tech, Atlanta, GA 30332-0150 \\ and \\ Richard E. Kreeger ${ }^{4}$ \\ NASA Glenn Research Center, Cleveland, OH 44135
}

\begin{abstract}
A three-dimensional Eulerian analysis has been developed for modeling droplet impingement on lifting bodes. The Eulerian model solves the conservation equations of mass and momentum to obtain the droplet flow field properties on the same mesh used in CFD simulations. For complex configurations such as a full rotorcraft, the Eulerian approach is more efficient because the Lagrangian approach would require a significant amount of seeding for accurate estimates of collection efficiency. Simulations are done for various benchmark cases such as NACA0012 airfoil, MS317 airfoil and oscillating SC2110 airfoil to illustrate its use. The present results are compared with results from the Lagrangian approach used in an industry standard analysis called LEWICE.
\end{abstract}

\section{Introduction}

$\mathrm{I}_{\mathrm{a}}^{\mathrm{n}}$ $\mathrm{n}$-flight icing of a helicopter is an interdisciplinary problem and an active area of concern. Icing affects the availability, safety and survivability of the rotorcraft due to degradation in performance caused by loss of lift, drag increase, and decrease in stall angle. A first step in modeling ice accretion is to estimate the rate at which water droplets collect on the solid surface. Advances in understanding and estimating water droplet impingement on aerodynamic bodies have been made through experimental studies and through the development of analytical and empirical tools over the past few decades. ${ }^{1-3}$

There have been two primary approaches for the prediction of surface droplet impingement distributionsLagrangian and Eulerian methods. Da Silveira et $\mathrm{al}^{4}$ have conducted an evaluation of these methods and found both methods to be equally effective. LEWICE or LEWICE3D are representative examples of industry-standard icing programs that use a Lagrangian approach to compute droplet trajectories through the air, and have been shown to be highly effective. ${ }^{5,6}$ In Lagrangian approaches, computational cost is reduced by performing the simulation of ice accretion only at a few selected strips in the configuration, as opposed to the full 3D simulation where collection efficiency is computed over the entire surface.

In the Eulerian approach, (e.g. FENSAP-ICE. ${ }^{7,8}$ ) the conservation of mass and momentum of the droplets are computed simultaneously with the flow field solution, by solving two additional governing equations for the volume fraction of water and the particle velocities. These equations are solved on the same CFD mesh. The mean flow may be unsteady, and the solid surfaces may be in relative motion. Most Lagrangian approaches, on the other hand, assume or require the flow field to be steady. For this reason, an Eulerian method is more attractive for modeling rotorcraft icing phenomena.

The present researchers, in collaboration with NASA and industries, have been working on the development of methods for modeling rotorcraft icing phenomena. In the past, this effort was based on Lagrangian approaches. ${ }^{9-14}$ The primary objective of the present study is to couple an existing CFD analysis with an Eulerian droplet solver and to verify the accuracy and the computational efficiency of this method for modeling droplet impingement. In order

\footnotetext{
${ }^{1,2}$ Graduate Research Assistant, School of Aerospace Engineering, Georgia Institute of Technology, 270 Ferst Dr, Atlanta, Georgia 30332-0150, Student Member, AIAA.

${ }^{3}$ Regents Professor and Associate Chair for Undergraduate Programs, School of Aerospace Engineering, Georgia Institute of Technology, 270 Ferst Dr, Atlanta, Georgia 30332-0150, AIAA Fellow, AIAA.

${ }^{4}$ Aerospace Engineer, Icing Research Branch, 21000 Brookpark Rd. Senior Member AIAA.
} 
to validate the present approach using Eulerian method, simulations are performed for various benchmark cases. The present computational results are compared with results from LEWICE simulations and test data.

\section{Icing model formulation}

Figure 1 shows the basic elements of the ice accretion simulation model. The process starts with grid generation and CFD flow analysis for a clean baseline configuration. The droplet solver reads the flow field data and computes the local collection efficiency $(\beta)$ on the surface. This information is fed into LEWICE which subsequently calculates the resulting ice shape that evolves over a period of time. The grid generator is next invoked to generate a new volume grid around the iced configuration, for use in the CFD solver for an updated flow filed. These modules are coupled to each other using a PYTHON script, and exchange the required data using industry-standard flow filed and grid format (PLOT3D). In the present study the focus is mainly on the development and validation of the Eulerian droplet solver.

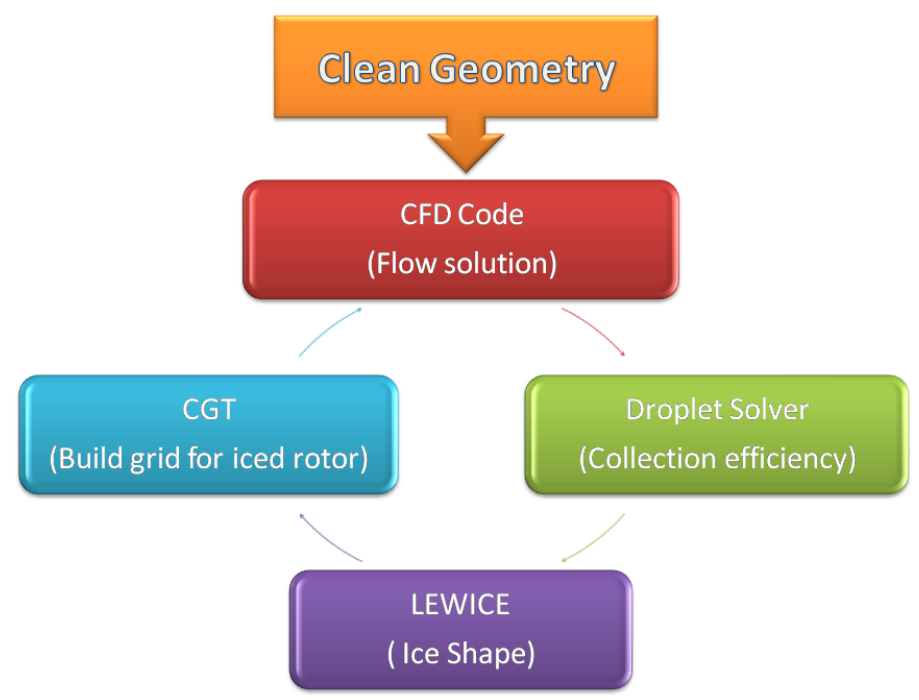

Figure 1. Overview of the Ice Accretion Analysis

\section{A. CFD solver}

A 3-D Reynolds-Averaged compressible Navier-Stokes solver called GENCAS (Generic Numerical Compressible Airflow Solver), developed by Min ${ }^{15,16}$ is used in this study to model the flow field. This solver may be used to solve the RANS equations on 2D or 3D structured multi-block grids. Roe's FDS and AUSMPW+ upwind schemes are available for inviscid flux computation. First or second order implicit LUSGS with Newton subiteration, or $2^{\text {nd }} / 4^{\text {th }}$ order explicit Runge-Kutta schemes are available for time marching. If a higher order spatial accuracy is desired, 3 rd order MUSCL, $5^{\text {th }}$ order WENO or a $7^{\text {th }}$ order WENO cell interface reconstruction methods may be selected. Available turbulence models include one equation Spalart-Allmaras (SA) and SA-DES models, and two equation Wilcox's $\kappa-\omega$, standard $\kappa-\varepsilon$, Menter's $\kappa-\omega / \kappa-\varepsilon$ BSL, Menter's $\kappa-\omega$ SST, KES, and HRKES models. For a detailed description of the numerical formulation of GENCAS, the reader is referred to the papers written by Min et al. . ${ }^{15,16}$

\section{B. Droplet solver}

In order to compute the droplet flowfield properties at the same nodes of the discrete domain where the flow variables of air are known, an Eulerian approach is used in the present study. In this method, the average water droplet properties within a control volume are solved instead of tracking individual particles. This physical approach has several advantages over the Lagrangian approach. These include improved quality of the solution, the ability to model unsteady flows over bodies in relative motion, and the automated treatment of shadow zones (no impingement) for probes or detector placing. ${ }^{17}$ The interaction between the air particles and the droplets occurs through a drag force exerted by the mean flow on the particles. The presence of the droplet flow field is not felt by the mean flowfield solver, and the droplets are treated as a passive scalar field. When the air flow is steady, the CFD analysis may be computed a priori and used in the droplet solver.

In the derivation of governing equations for air-droplet flows, the following assumptions are made ${ }^{18}$ : 
- The droplets have a spherical shape and do not undergo any deformation or breaking.

- There is no collision, or coalescence between droplets.

- There is no exchange of heat and mass between the droplets and the surrounding air.

- The effect of mean flow mixing effects on the droplet is neglected.

- Drag, gravity and buoyancy due to density differences are the only forces acting on the droplets.

The first two assumptions are based on the fact that the size of icing droplets is 1-100 $\mu \mathrm{m}$ range and droplet flow is considered dilute with a volume fraction around $10^{-6}$. Although the gravity and buoyancy forces are three orders lower in magnitude than drag force in typical flight conditions, these forces are kept in the model because their effects could be significant in the simulation of de-icing fluid contamination by rain and snow during ground operation.

The governing equations for the conservation of mass and momentum of the droplets are written as follows:

$$
\frac{\partial \alpha}{\partial t}+\nabla \cdot\left(\alpha u_{i}\right)=0
$$

Here, $\alpha$ is defined as the non-dimensionalized volume fraction of water; $u_{i}$, the non-dimensionalized velocity of droplets.

$$
\frac{\partial u_{i}}{\partial t}+u_{i} \cdot \nabla u_{i}=\frac{C_{D} \operatorname{Re}_{d}}{24 K}\left(u_{a}-u_{i}\right)+\left(1-\frac{\rho_{a}}{\rho}\right) \frac{1}{F r^{2}} g_{i}
$$

Here, $u_{a}$ is the non-dimensionalized velocity of air; $\rho$, the density of water; $\rho_{a}$, the density of air; $g_{i}$, gravity vector; $F_{r}=U_{\infty} / \sqrt{L g}$ is the Froude number; $U_{\infty}$, the speed of air at freestream; $L$, the characteristic length (typically the airfoil chord length); $K=\rho d^{2} U_{\infty} / 18 L \mu$, an inertia parameter; $\mu$, the dynamic viscosity of air.

The first term on the right-hand-side of the momentum equation accounts for the drag acting on the droplet or particle based on low-Reynolds number, or Stokes flow, behavior for spheres. ${ }^{19}$ The droplets Reynolds number $\left(\operatorname{Re}_{\mathrm{d}}\right)$ is defined based on the slip velocity between the air and droplet and the droplet diameter. The drag coefficient is

$$
\begin{aligned}
C_{D} & =\frac{24}{\operatorname{Re}_{d}}\left(1+0.15 \mathrm{Re}_{d}{ }^{0.687}\right) & \operatorname{Re}_{d} & \leq 1000 \\
C_{D} & =0.4 & \operatorname{Re}_{d} & >1000
\end{aligned}
$$

with,

$$
\operatorname{Re}_{d}=\frac{\rho_{a} d U_{\infty}\left|u_{a}-u_{i}\right|}{\mu} .
$$

Equations (1) and (2) are recast in finite volume form using divergence theorem. A first order upwind scheme is employed for computing the mass and momentum flux at the faces of the control volume. An implicit time marching algorithm is employed. Mean flow quantities are lagged by one time step compared to particle velocity and volume fraction. The resulting system of banded linear equations is solved using an approximate factorization scheme.

The freestream values of droplet velocity and volume fraction are imposed as boundary conditions at the far field. Prescribing the correct boundary conditions for the droplets at the wall is not straight-forward. The droplet velocity cannot be simply set to zero on the walls. A switching boundary condition ${ }^{20}$ is applied. Volume fraction and velocity of droplets are extrapolated from the computed flux entering the control volumes adjacent to the solid. A lower bound of volume fraction and zero velocity are imposed on flux exiting the flowfield, and collecting on the walls.

$$
\begin{aligned}
& \alpha_{\mathrm{w}}=\alpha_{\mathrm{w}-1} \text { and }_{\mathrm{i}, \mathrm{w}}=\mathrm{u}_{\mathrm{i}, \mathrm{w}-1} \text { Incomingdropletfluxes } \\
& \alpha_{\mathrm{w}}=f_{\alpha} \text { and } \mathrm{u}_{\mathrm{i}, \mathrm{w}}=0 \quad \text { Dropletflux exitingthe wall }
\end{aligned}
$$

A common way of comparing droplet impingement rate at various flight conditions is through the collection efficiency $(\beta)$. This quantity characterizes the configuration's ability to capture incoming water and is defined as the local mass flux of water onto the airfoil surface normalized by the freestream liquid water content and the freestream velocity.

$$
\beta=\frac{\alpha \rho_{w} u_{i}}{(L W C) U_{\infty}} \frac{A_{i}}{|A|}
$$

where, $A_{\mathrm{i}}$ is the local area normal; $L W C$, Liquid water content (Fig. 2).

Computational prediction for large droplet case and found to show a considerably higher collection efficiency distribution and the peak value is greater than the measurement. ${ }^{21}$ A plausible reason for this over prediction is droplet splashing and breakup. ${ }^{21}$ In present study, the effect of droplet splashing is investigated by using a model 
proposed in Ref. 22. Splashing causes a reduction in collection efficiency. The mass faction of water lost due to bouncing $\left(\mathrm{N}_{\mathrm{b}}\right)$ is first computed.

$$
N_{b}=0.2\left[1-\exp \left(-0.85\left(\sqrt{K_{t n}}\right)\right) \mid\right.
$$

where

$$
\begin{gathered}
K_{t n}=0.859\left(\frac{\rho_{w}}{L W C}\right)^{0.125} \sqrt{K} \\
K=\frac{\mu_{w}}{\rho_{w} \sigma d}\left(\frac{\rho_{w}\left|u_{a}-u_{i}\right| d}{\mu_{w}}\right)^{1.25}
\end{gathered}
$$

Here, $\sigma$ is surface tension between air and water. Finally the collection efficiency is computed as

$$
\beta^{\prime}=\beta\left(1-N_{b}\right)
$$

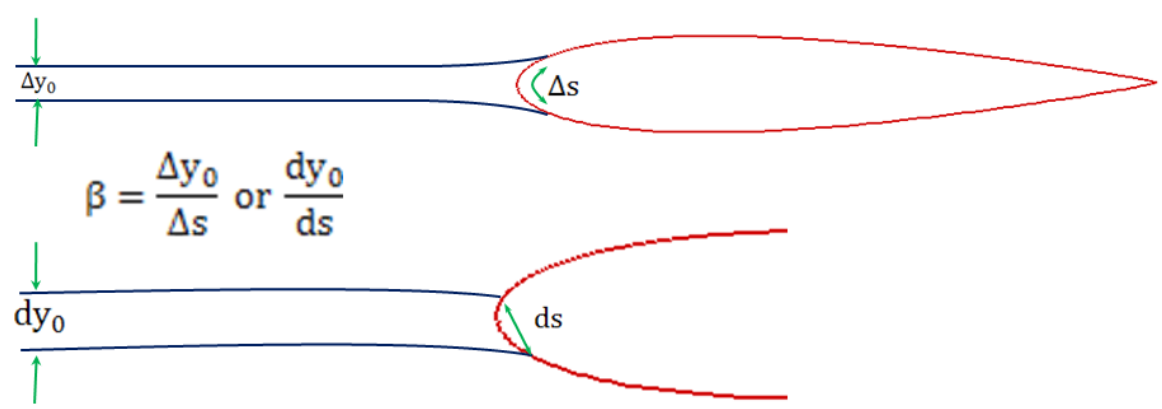

Figure 2. Definition of Collection Efficiency

\section{Results}

In this section, a number of calculations are presented to demonstrate the capabilities of the present Eulerian approach. Comparisons with industry-standard Lagrangian approaches found in LEWICE are also shown.

\section{A. NACA0012 airfoil}

Collection efficiency estimates have been done for NACA0012 airfoil, at three different angles of attack. The simulations are performed at a 0.31 free-stream Mach number with a constant droplet diameter of $20 \mu \mathrm{m}$ and an airfoil chord of $0.5334 \mathrm{~m}$. The mean flow field is obtained from GENCAS. ${ }^{15-16}$ In the CFD simulation, Roe scheme with a 3rd order MUSCL reconstruction is used for flux calculations. A first order implicit LU-SGS scheme is used for marching in time. Spalart-Allmaras (SA) is used as the turbulence model.

Figure 3 shows a comparison of the collection efficiency from the present Eulerian simulations with the LEWICE Lagrangian results. ${ }^{20}$ In general, the present results are in good agreement with LEWICE, providing confidence in the present method. It is found that the deviation between the two approaches grows with increased angles of attack. Similar discrepancies have been reported by Kinzel et al. ${ }^{20}$ and Beaugendre et al. ${ }^{23}$ in their comparisons between FENCAP-ICE and LEWICE. For the $\alpha=4 \mathrm{deg}$. the results from LEWICE are obtained at corrected angle of attack ( $3.5 \mathrm{deg}$.).

Table 1. Test Conditions for MS317 Airfoil

\begin{tabular}{|c|c|}
\hline Parameter & Value \\
\hline Chord $(\mathrm{m})$ & 0.914 \\
\hline $\mathrm{U}_{\infty}(\mathrm{m} / \mathrm{sec})$ & 78.66 \\
\hline $\operatorname{Re}($ Million$)$ & 4.83 \\
\hline AOA $($ Degree $)$ & $0 / 8$ \\
\hline MVD $(\mu \mathrm{m})$ & $11.5 / 21.0 / 92.0$ \\
\hline
\end{tabular}




\section{B. MS317 airfoil}

Next, the collection efficiency simulations are reported for the MS317 airfoil. This configuration was chosen because of the availability of collection efficiency and pressure distributions data at various mean flow conditions, collected over 1997 and $1999 .{ }^{24}$ GENCAS is used to obtain flowfield data. In the CFD simulation, Roe scheme with a 3rd order MUSCL reconstruction is used for flux calculations. $1^{\text {st }}$ order implicit LUSGS scheme is used for marching in time. Spalart-Allmaras (SA) is used as a turbulence model. The predicted pressure distributions are compared with experimental data in Fig. 4. Predicted pressure distributions at the bottom surface are in good agreement with experiment. Some differences between the computed and measure pressure distributions are observed near the trailing edge, but this is expected to play on a minor role in the collection efficiency near the leading edge.

The effect of median volumetric diameter (MVD) on collection efficiency is investigated. The icing test conditions are given in table 1 . The effect of first cell distance normalized by chord length was also investigated because the droplet solver updated the values at boundary by using the values of first inner cell. It is found that the collection efficiency is relatively insensitive to the normal height of the first row of cells over the wall. It is expected that the deviation in the flowfield between present simulation and the test data would only have a negligible effect on the collection efficiency distribution around the leading edge. In the experiment, collection efficiency was measured for 0 and 8 degree of angle of attack and MVDs of 11.5, 21, and $92 \mu \mathrm{m}$.

Figure 5, 6 present the comparison of local impingement efficiency distributions between present prediction and measurement according to different value of MVD at $0^{\circ}$ and $8^{\circ}$. The $\mathrm{x}$-axis (surface distance) is normalized by airfoil chord length. The positive values correspond to the lower surface of the airfoil. The peak value of collection efficiency increases with MVD size. For an angle of attack of $0^{\circ}$, the laser system shows higher impingement efficiency values near the region of maximum impingement efficiency. In Ref. 24, the reason for this discrepancy is explained. It was attributed to a small level of dye penetration into the blotter. In the present simulation, the impingement limits are under-predicted except for the $92 \mu \mathrm{m}$ case for which the predicted collection efficiency is considerably higher and the peak value is greater than the measurement. A similar over-prediction is seen in the results from LEWICE in Ref. 24. Possible reasons for these large differences between simulation and experiment was investigated in Ref. 24. One of the cited reasons was the errors associated with measuring MVD for the 92-94 $\mu \mathrm{m}$ cases. Another plausible reason is droplet splashing and breakup.

Additional studies were performed for this test condition and it was found that droplet splashing and breakup occurs near the airfoil leading edge region. For the high angle of attack case, the location of peak value of collection efficiency was shifted downstream on the lower surface of the airfoil. Simulation results are shifted to the left with respect to the experimental data, if the angle of attack is not corrected for wall effects.

The effect of first cell distance on collection efficiency is investigated in Fig 5-(b). Marginal difference in collection efficiency is observed. The effect of droplet splashing is investigated in Figures 5-(c) and 6-(c). An improvement in the prediction is seen when the collection efficiency is modified to account for splashing.

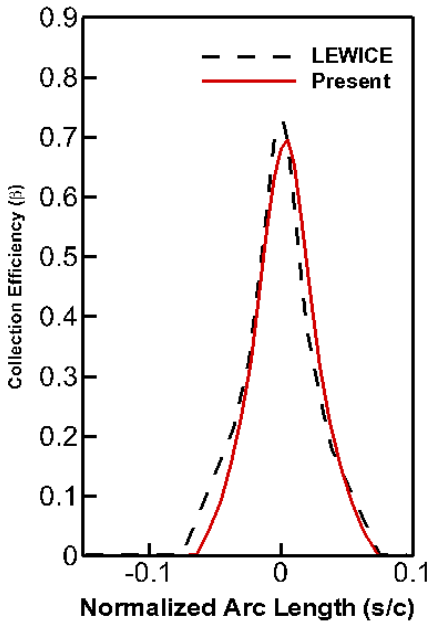

(a) $\alpha=\mathbf{0}$ deg.

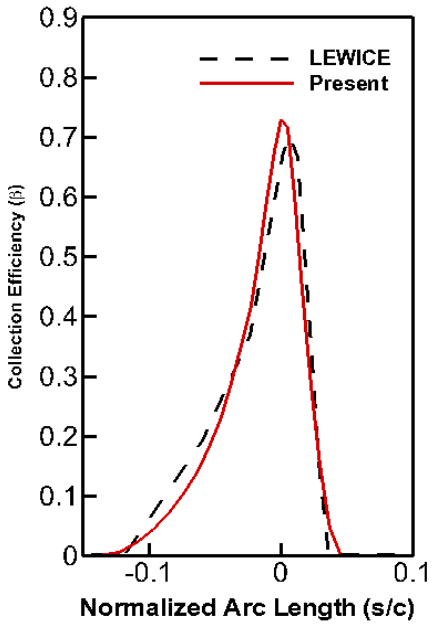

(b) $\alpha=4$ deg.

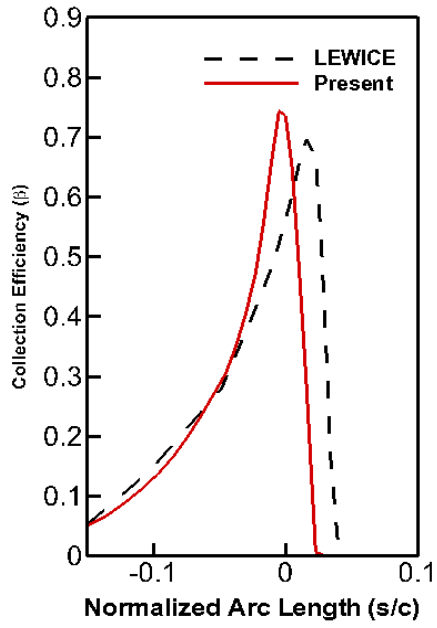

(c) $\alpha=\mathbf{8}$ deg.

Figure 3. Comparison of Predicted versus LEWICE Collection Efficiencies for a NACA0012 Airfoil (Wall Corrections have not been used in the simulations) 


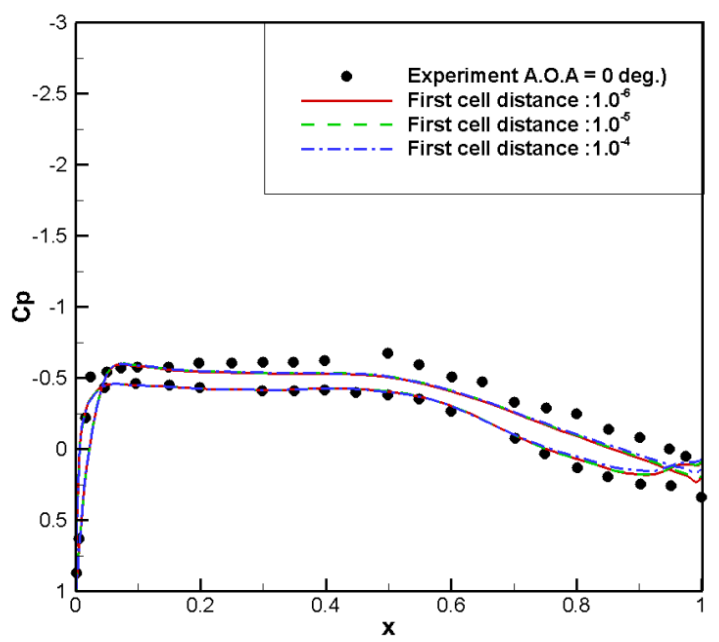

Figure 4. Comparison of Pressure Distribution for MS317 Airfoil

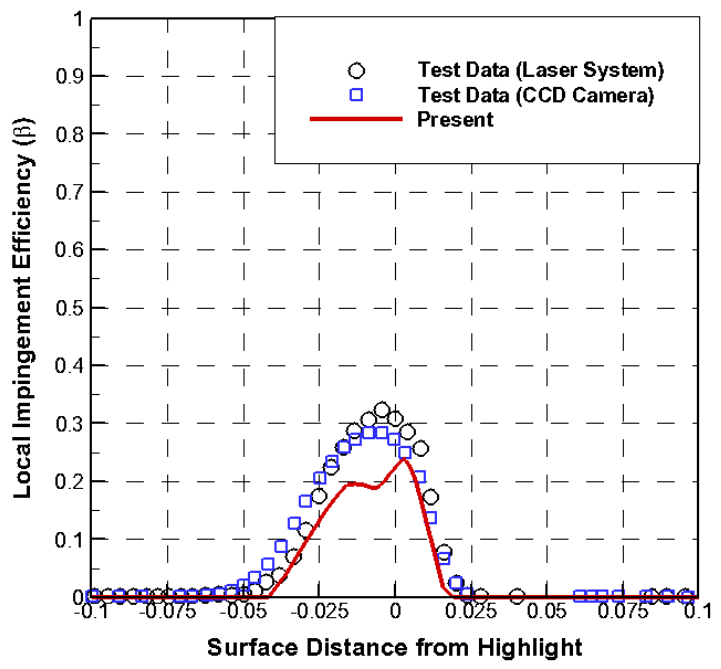

(a) $\mathrm{MVD}=\mathbf{1 1 . 5}$

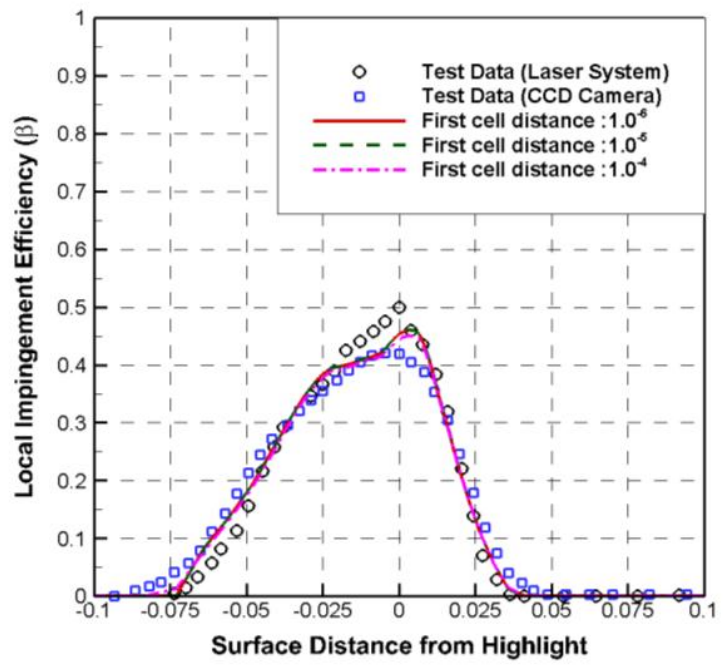

(b) $\mathrm{MVD}=21$

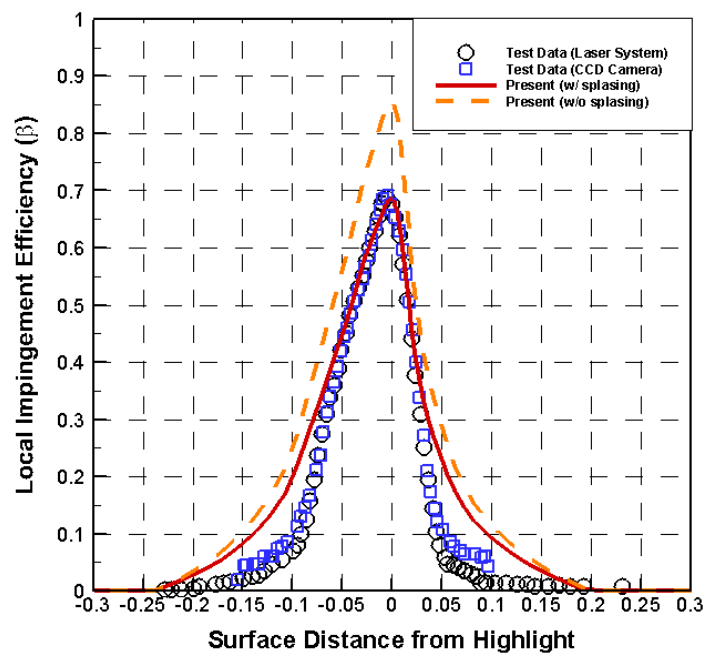

(c) $\mathrm{MVD}=92$

Figure 5. Comparison of Collection Efficiency for MS317 airfoil at Zero Angle of Attack

American Institute of Aeronautics and Astronautics 


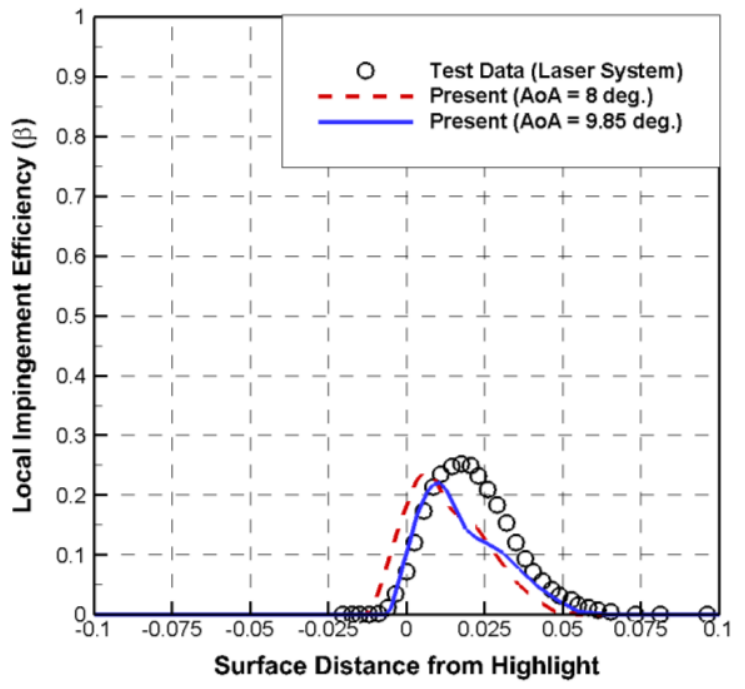

(a) $\mathrm{MVD}=11.5$

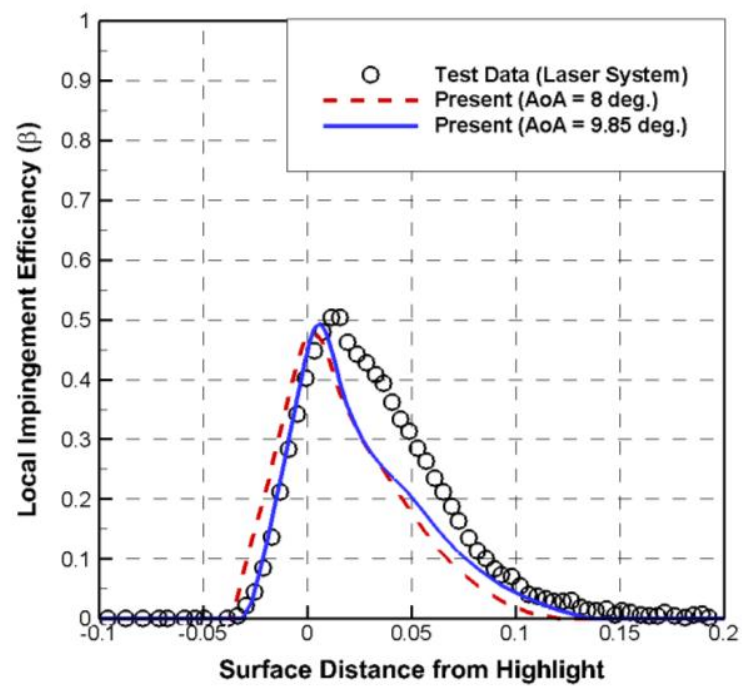

(b) $M V D=21$

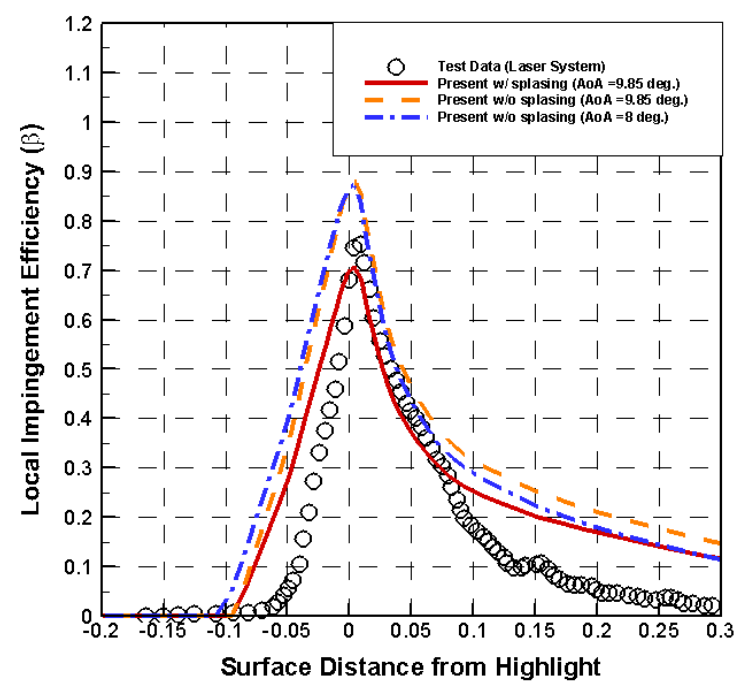

(c) MVD=92

Figure 6. Comparison of Collection Efficiency for MS317 airfoil at 8 Degrees Angle of Attack

\section{Oscillating SC2110 airfoil}

Collection efficiency calculations have been performed for an oscillating SC2110 airfoil and comparisons with LEWICE have been made. The airfoil has a chord length of $0.381 \mathrm{~m}$, and operates at a freestream Mach number of 0.4208. Unsteady flowfield data for each angle of attack were obtained using a version of OVERFLOW.

The simulations employ a nominal MVD size of $22 \mu \mathrm{m}$. The collection efficiency is computed for $-1,-0.75,0.15$, 5, 8.53 and 11 degrees of angle of attack. Comparisons of collection efficiency between the present simulation and LEWICE for oscillating SC2110 airfoil are presented in Fig. 7 at several angles of attack. The present Eulerian approach shows a spatial distribution of collection efficiency similar to LEWICE. The peak values from the two approaches are in reasonable agreement. It is found that the present Eulerian simulation shows a wider surface region with significant collection of water droplets compared to the Lagrangian simulation. 


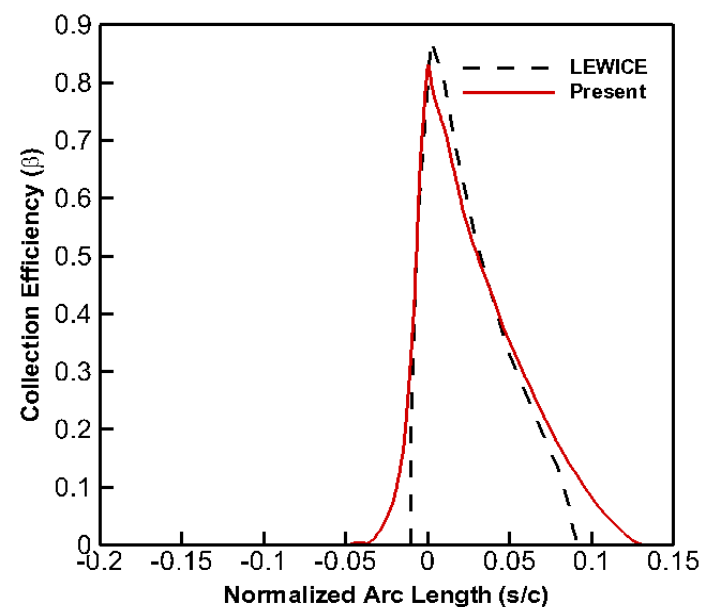

(a) $\alpha=-1$ deg.

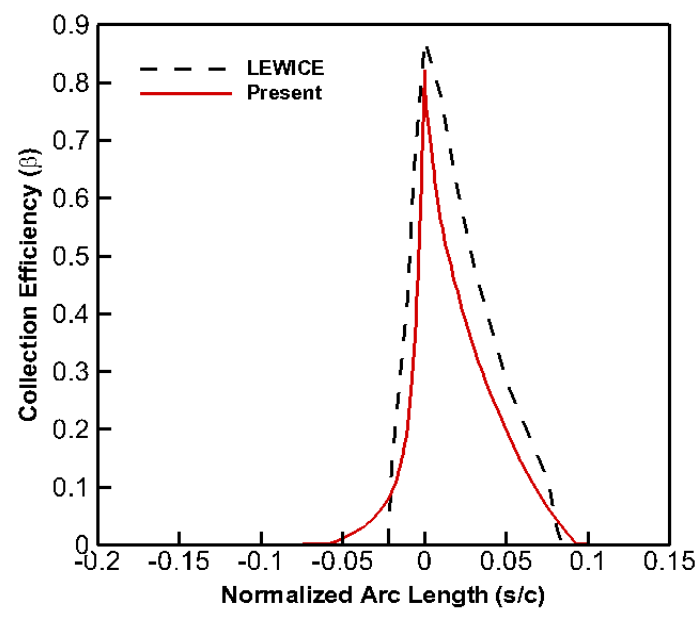

(c) $\alpha=0.15$ deg.

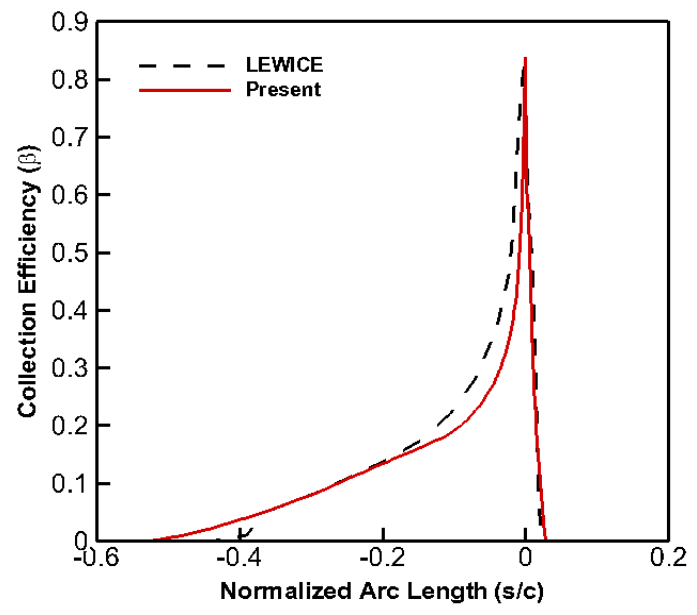

(e) $\alpha=8.53 \mathrm{deg}$.

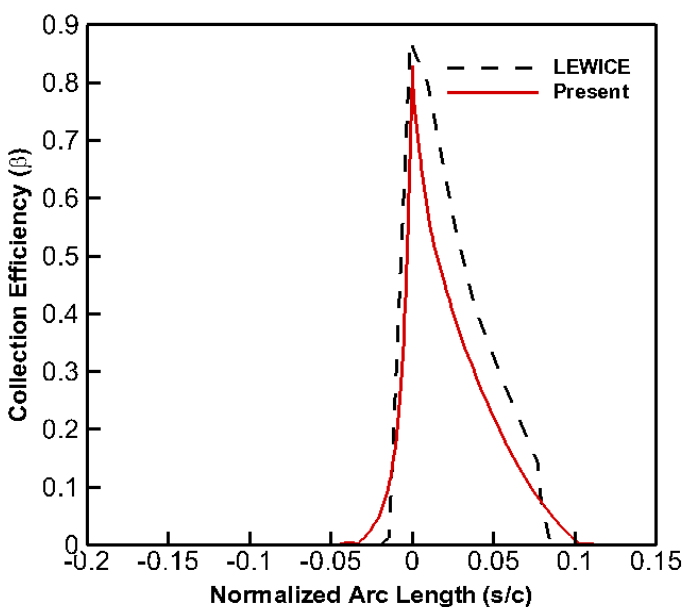

(b) $\alpha=-0.71 \mathrm{deg}$.

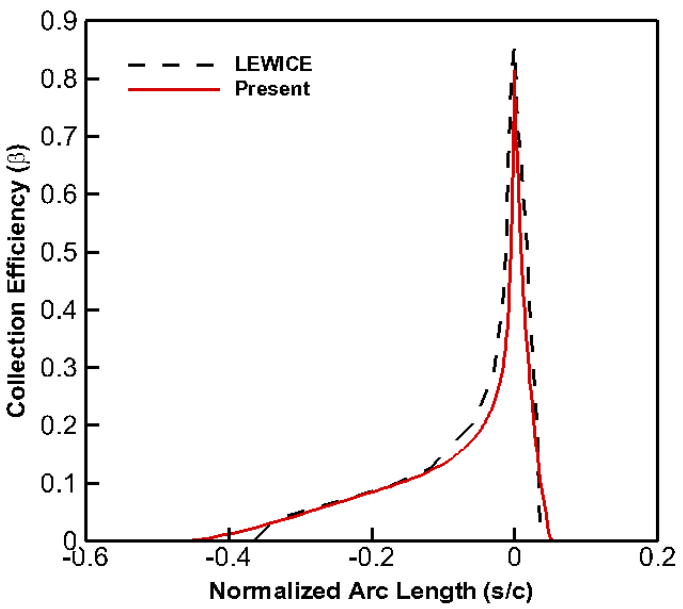

(d) $\alpha=5$ deg.

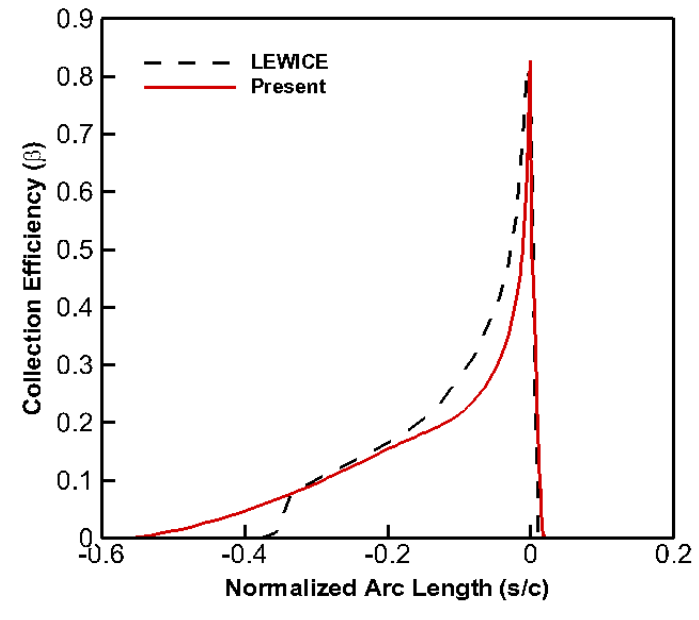

(f) $\alpha=11 \mathrm{deg}$.

Figure 7. Comparison of Collection Efficiency for an Oscillating SC2110 Airfoil

8

American Institute of Aeronautics and Astronautics 
Table 2. Test Conditions for NACA64A008 Swept Tail

\begin{tabular}{|c|c|}
\hline Parameter & Value \\
\hline $\mathrm{U}_{\infty}(\mathrm{m} / \mathrm{sec})$ & 78.66 \\
\hline $\operatorname{Re}($ Million$)$ & 5.03 \\
\hline AOA $($ Degree $)$ & $0 / 6$ \\
\hline MVD $(\mu \mathrm{m})$ & $11.5 / 21.0$ \\
\hline
\end{tabular}

\section{NACA64A008 Swept Tail}

In an effort to assess the suitability of the present approach for 3-D configurations, collection efficiency simulations have been done for a swept tail made of NACA64A008 sections. This configuration was chosen because of the availability of collection and pressure distributions data at various mean flow conditions, collected over 1997 and $1999 .{ }^{24}$ GENCAS is used to obtain flowfield data. The predicted pressure distributions are compared with experimental data in Fig. 7 and are in good agreement with experiment.

The icing test conditions are given in Table 2. Figure 9 and 10 present the comparison of local impingement efficiency distributions between present prediction and measurement according to different value of MVD at $0^{\circ}$ and $6^{\circ}$. The $\mathrm{x}$-axis (surface distance) is normalized by airfoil chord length. The positive values correspond to the lower surface of the tail section. The peak value of collection efficiency is found to increase with MVD size. For an angle of attack of $0^{\circ}$, the peak values of collection efficiency are under-predicted. For the high angle of attack case, the location of peak value of collection efficiency was shifted downstream on the lower surface of the airfoil. Simulation results are shifted to the left with respect to the experimental data.

\section{Conclusions}

A 3D Eulerian based stand-alone solver has been developed and tested for various benchmark cases. The present Eulerian based solver has been shown to successfully predict collection efficiencies on two-dimensional and quasi three dimensional airfoils. The present approach is also in reasonable agreement to a well-validated Lagrangian code (LEWICE).

\section{Acknowledgments}

This project was funded by the U. S. Army under the Vertical Lift Research Center of Excellence (VLRCOE) program managed by the National Rotorcraft Technology Center, Aviation and Missile Research, Development and Engineering Center under Cooperative Agreement W911W6-06-2-0010 between Georgia Institute of Technology and the U. S. Army Aviation Applied Technology Directorate. Dr. Michael Rutkowski and Dr. John Berry are the technical monitors. The authors would like to acknowledge that this research and development was accomplished with the support and guidance of the NRTC. The views and conclusions contained in this document are those of the authors and should not be interpreted as representing the official policies, either expressed or implied, of the Aviation and Missile Research, Development and Engineering Center or the U.S. Government.

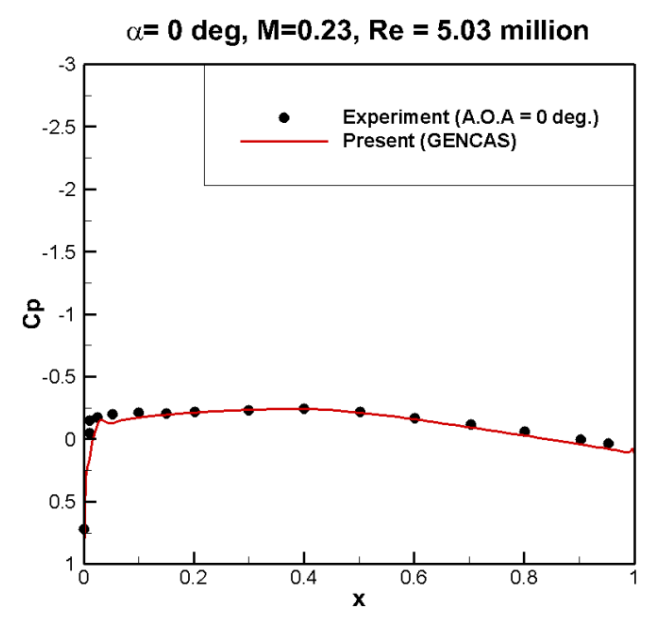

(a) $\alpha=0$ deg.

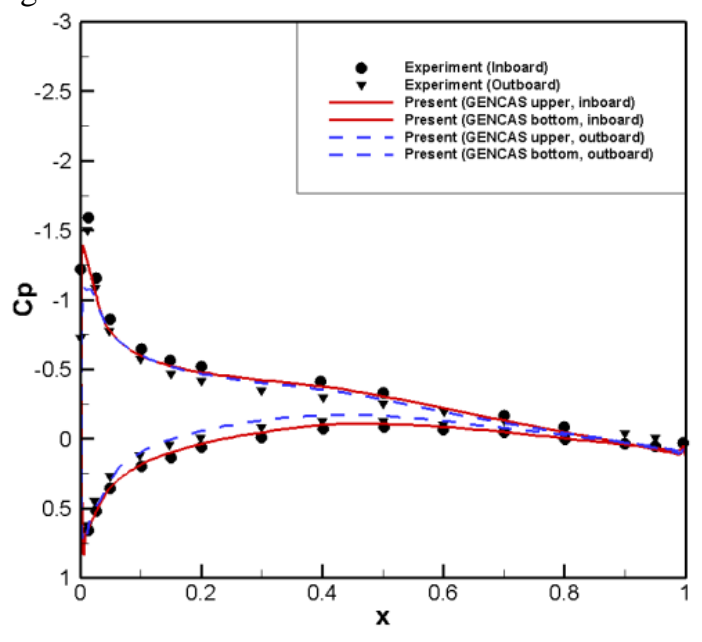

(b) $\alpha=6$ deg.

Figure 8. Comparison of Pressure Distribution for NACA64A008 Swept Tail Section

9

American Institute of Aeronautics and Astronautics 


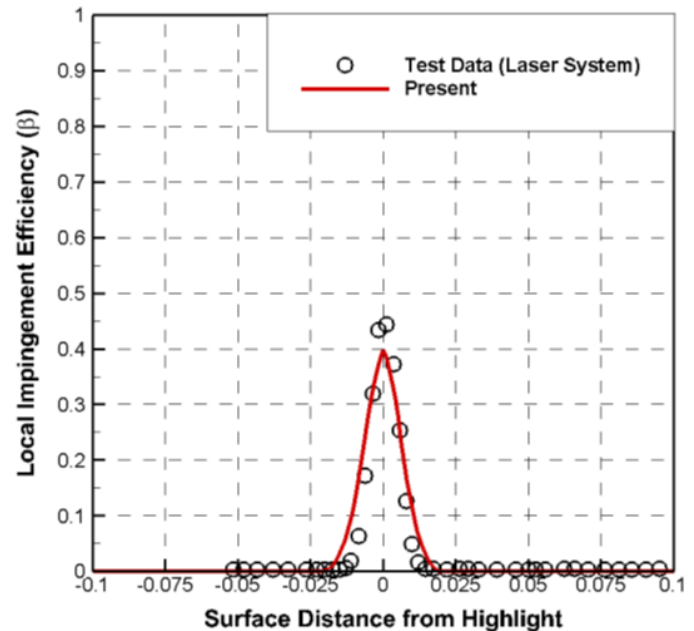

(a) $\mathrm{MVD}=\mathbf{1 1 . 5}$

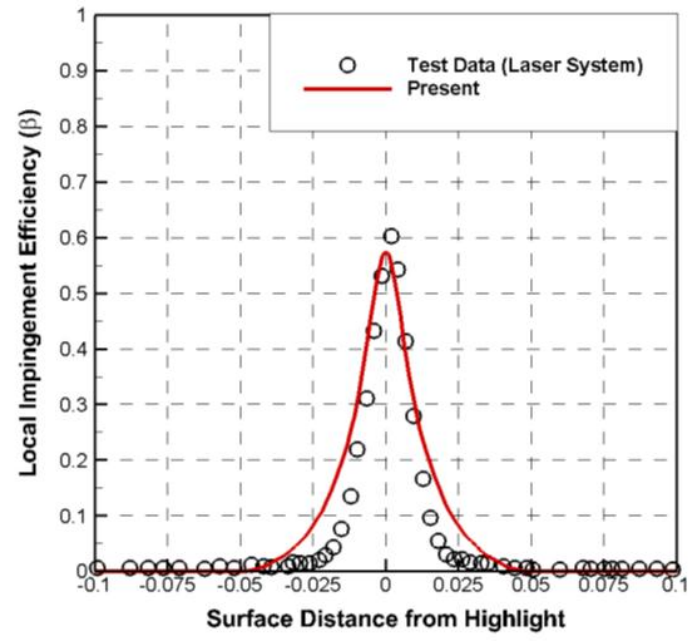

(b) $M V D=21$

Figure 9. Comparison of Collection efficiency for NACA64A008 Swept Tail Section at Zero Degrees Angle of Attack

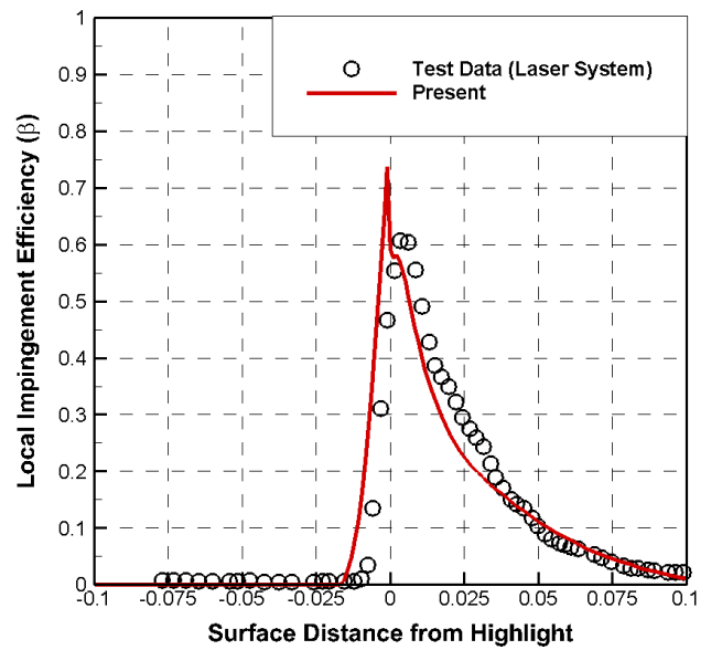

Figure 10. Comparison of Collection Efficiency for NACA64A008 Swept Tail at 6 Degrees Angle of Attack (MVD=21)

\section{References}

${ }^{1}$ Bell, J.D., "Icing at the McKinley Climatic Laboratory, an Update of the New Icing Capability Project," AIAA Paper 20040735, January 2004.

${ }^{2}$ Britton, R.K., "Ice Accretion Characteristics of a Model Rotor in the NASA Lewis Icing Research Tunnel," AHS International Icing Symposium 1995 Proceedings, September 1995.

${ }^{3}$ Flemming, R.J., Murty, H., Papadakis, Michael, and Wong, See-Ho, "Design, Fabrication, and Testing of Simulated Ice Shapes for the S-92A Helicopter,” AIAA Paper 2004-0736, January 2004.

${ }^{4}$ da Silveira, R. A., Maliska, C. R., Estivam, D. A., and Mendes, R., "Evaluation of Collection Efficiency Methods for Icing Analysis," Proceedings of COBEM 2003, 2003.

${ }^{5}$ Bidwell, C. S. and Potapczuk, M. G., "Users Manual for the NASA Lewis Three-Dimensional Ice Accretion Code (LEWICE3D),” Tech. Report, NASA Glenn Research Center, 1993. 
${ }^{6}$ Wright, W. B., "LEWICE 2.2 Capabilities and Thermal Validation,” AIAA Paper 2002-0383, 2002.

${ }^{7}$ Beaugendre, H., Morency, F., and Habashi, W., "FENSAP-ICE's Three-Dimensional In-Flight Ice Accretion Module: ICE3D," Journal of Aircraft, Vol. 40 No.2, 2003.

${ }^{8}$ Bourgault, Y., Boutanios, Z., and Habashi, W. G., "Three-Dimensional Eulerian Approaches to Droplet Impingement Simulations Using FENSAP-ICE, Part 1: Model, Algorithm, and Validation,” Journal of Aircraft, Vol. 37 No.1, 2000.

${ }^{9}$ Kwon, O. J. and Sankar, L. N., "Numerical Simulation of the Flow about a Swept Wing with Leading Edge Ice Accretions," Computers and Fluids, Vol. 26, No. 2, pp. 183-192, 1997.

${ }^{10}$ Sankar, L. N., Kwon, 0. J., Bangalore, A., Phaengsook, N. and Mello, O., "Effects of Icing on the Performance of Lifting Surfaces," Invited Lecture, Workshop on Aircraft Icing and Transition, Ecole Polytechnique, University of Montreal, Montreal, Canada, September 20-21, 1993.

${ }^{11}$ Rajmohan, N., Bain, J., Nucci, M., Sankar, L. N., Flemming, R., Egolf, T. A., and Kreeger, R. E., "Icing Studies for the UH-60A Rotor in High Speed Forward Flight," Proceedings of the 2010 AHS Aeromechanics Specialists Conference, San Francisco, CA, January 2010.

${ }^{12}$ Bain, J., Sankar, L. N., Nucci, M., Egolf, A., and Flemming, R. J., “A Methodology for Modeling the Effects of Icing on Rotary Wing Aerodynamics," Proceedings of the 2010 European rotorcraft Forum, September 2010.

${ }^{13}$ Bain, J., Sankar, L. N.,Deresz, R., Egolf, T. A., Flemming, R. J., and Kreeger, R., "Effects of Icing on Rotary Wing Loads and Surface Heat Transfer Rates," AIAA-2011-1100, 49th AIAA Aerospace Sciences Meeting including the New Horizons Forum and Aerospace Exposition, Orlando, Florida, Jan. 4-7, 2011.

${ }^{14}$ Bain, J., Sankar, L. N., Garza, D., Aubert, R. J., and Flemming, R. J., "A Methodology for the Prediction of Rotor Blade Ice Formation and Shedding," Proceedings of the SAE 2011 Aircraft and Engine icing and Ground Testing Conference, June 13-17, 2011.

${ }^{15}$ Min, B. Y. and Sankar, L. N., "Enhancements to a Hybrid Navier-Stokes/Free Wake Method for Improved Prediction of Blade-Vortex-Interaction Phenomena," AIAA 2009-3860, 27th AIAA Applied Aerodynamics Conference, San Antonio, Texas, June 22-25, 2009.

${ }^{16}$ Min, B. Y., Lee, W., Englar, R. and Sankar, L. N., "Numerical Investigation of Circulation Control Airfoils," Journal of Aircraft, vol. 46, No. 4, pp. 1403-1410, 2009.

${ }^{17}$ Beaugendre, H,Morency, Habashi, W, D., " FENSAP-ICE's three-dimensional in-flight ice accretion module - ICE3D," Journal of Aircraft, Vol. 40, No. 2 pp. 239-247, 2003.

${ }^{18}$ Bourgault, Y., Habashi, W.G., Dompierre, J. and Baruzzi, G.S., "A Finite Element Method Study of Eulerian Droplets Impingement Models", International Journal for Numerical Methods in Fluids, Vol. 29, pp. 429-449, 1999.

${ }^{19}$ Michaelides, E. E., Particles, Bubbles \& Drops: Their Motion, Heat and Mass Transfer, World Scientific Publishing Company, April 2006.

${ }^{20}$ Michael P. Kinzel, Christian M. Sarofeen, Ralph W. Noack, Richard E. Kreeger, "A Finite-Volume Approach to Modeling Ice Accretion," AIAA Paper 2010-4230, June 2010.

${ }^{21}$ M. Papadakis, K. E. Hung, G. T. Vu, H. Wei Yeong, C. S. Bidwell, M. D. Breer, and T. J. Bencic, "Experimental Investigation of Water Droplet Impingement on Airfoils, Finite Wings, and an S-Duct Engine Inlet," NASA, TM-2002-211700, October 2002.

${ }^{22}$ William Wright, "User's Manual for LEWICE Version 3.2," NASA, CR-2008-214255, November 2008.

${ }^{23} \mathrm{H}$. Beaugendre, F. Morency and W.G. Habashi, "Development of a Second Generation In-flight Icing code", ASME Journal of Fluids Engineering, March 2006.

${ }^{24}$ M. Papadakis, K. E. Hung, G. T. Vu, H. Wei Yeong, C. S. Bidwell, M. D. Breer, and T. J. Bencic, "Experimental Investigation of Water Droplet Impingement on Airfoils, Finite Wings, and an S-Duct Engine Inlet," NASA, TM-2002-211700, October 2002.

${ }^{25}$ Rajmohan, N., "Application of Hybrid Methodology to Rotors in Steady and Maneuvering Flight", Ph.D. Dissertation, Georgia Institute of Technology, 2010 . 